\section{Brain failure after eighty years}

\author{
T.J. Crow
}

Normal Aging, Alzheimer's Disease and Senile Dementia: Aspects on Etiology, Pathogenesis, Diagnosis and Treatment. Edited by C.G. Gottries. Editions de l'Université de Bruxelles, Avenue Paul Heger 26, Bruxelles, Belgium:1985. Pp.308. FB 992.

IN 1907, Alois Alzheimer described the thickening and tortuosity of fibrils within the neuronal cytoplasm of almost every fourth cell of the cerebral cortex of a 51year-old woman who had been suffering from dementia. At that time he can have had little conception of the growth of interest in the phenomenon 80 years later. What may then have seemed an isolated pathological curiosity now appears as but one manifestation of an ubiquitous process whose relevance to ageing itself is the centre of discussion. What has become known as "Alzheimer-type dementia" is now generally agreed to include not only the unusual cases of presenile dementia (onset before 65 years of age) such as Alzheimer described, but also the great mass of dementias of old age. The prevalence of this condition is $5-8$ per cent of the population at the age of 65 , rising to 20 per cent at age 80 and $40-50$ per cent above the age of 90 years.

The neuropharmacological aspects of the subject have been one of the features of recent research, and these proceedings record the contributions to two symposia at the Collegium Internationale NeuroPsychopharmacologicum in Florence in 1984. Since 1976 it has been recognized that the cholinergic projections to the cerebral cortex are lost, giving rise to hopes that cholinergic replacement therapy might ameliorate some part of the psychological deficit. Such hopes are as yet unfulfilled. One problem, well documented in this volume, is that the cholinergic losses are far from isolated - there is evidence of loss of adrenergic and serotonergic projections as well. Whether the primary change occurs in the cell bodies of origin of the ascending systems, or whether these systems are affected secondarily to changes in the cortex itself (the temporal areas being a probable site of early change), is still a matter of debate, although opinion is swinging towards the latter possibility. Whichever viewpoint is correct, the anatomical and chemical selectivity of the process is surprising; in the cortex, for example, somatostatincontaining neurones are affected and cholecystokin and vasoactive intestinal polypeptide-containing cells are spared (see Nature 314, 92-94; 1985). This may yet provide a clue to the origin of the Alzheimer process.

Contributions to the book are not confined to neuropharmacology. They touch also on aetiology, both with respect to the enigmatic role of aluminium and to genetic factors (Alzheimer's disease shares with two other neurodegenerative conditions, Parkinson's disease and amyotrophic lateral sclerosis, a tendency to an earlier age of onset when there is greater incidence of familial cases). Aluminium is now known to be present in high concentration in the amyloid plaque, the structure which, together with the neurofibrillary tangle described by Alzheimer is the hallmark of the disease. Whether the element accumulates as a secondary effect or plays a pathogenic role remains unclear. In a short chapter, D.R.C. McLachlan speculates that aluminium could interact with calcium to contribute to the pathology. That electrolyte changes may be relevant to the aetiology of neurodegenerative disease is also suggested by Gajdusek and Garruto; they attribute the high incidence of amyotrophic lateral sclerosis and Parkinson's disease on Guam, the Kii peninsula of Japan and an area of New Guinea to low concentrations of calcium and magnesium in the soil, and the subsequent decline in incidence to correction of these mineral deficiencies. Such secular changes challenge the therapeutic nihilism which may be generated by the suspicion that these diseases, along with Alzheimer's dementia, are inseparable from the molecular genetic mechanisms of ageing.

This volume thus deals with a number of aspects of recent progress on Alzheimer's disease. There is relatively little reflection of the current interest in the protein structure of the plaques and tangles, but drug treatment strategies, although as yet of little practical value, are well covered.

T.J. Crow is in the Division of Psychiatry, Clinical Research Centre, Northwick Park Hospital, Watford Road, Harrow, Middlesex HAI 3UJ, $U K$.

\section{New editions}

- Microbes and Man, 2nd Edn, by John Postgate (Penguin; pbk £4.95, \$6.95)

- Methods in Plant Ecology, 2nd Edn, edited by P.D. Moore and S.B. Chapman (Blackwell Scientific; hbk $£ 34.80, \$ 57$, pbk $£ 23.80, \$ 36$ ).

- Statistics and Data Analysis in Geology, 2nd $E d n$, by John C. Davies (Wiley; hbk $\$ 52.55$, $£ 40.35$, pbk $\$ 24.95, £ 18.95$ )

- Superfluidity and Superconductivity, 2nd $E d n$, by D.R. Tilley and J. Tilley (Adam Hilger; hbk $£ 36, \$ 60$, pbk $£ 18, \$ 25$ ).

- Partition of Cell Particles and Macromolecules, 3rd Edn, by Per-Åke Albertsson (Wiley; $\$ 59.95, £ 61.85$ ).

- Chromatographic Methods, 4th Edn, by A. Braithwaite and F.J. Smith (Chapman \& Hall; hbk $£ 29, \$ 65$, pbk $£ 12.95, \$ 27)$

- The Colour Science of Dyes and Pigments, 2nd Edn, by K. McLaren (Adam Hilger; $£ 19.50$, \$35).

\section{Plenum:} Making It Happen

\section{Forthcoming ... CHEMISTRY BY COMPUTER}

An Overview of the Applications of Computers in Chemistry

by Stephen Wilson

In this wide-ranging survey, Dr. Wilson covers the techniques of computational chemistry and shows how they may be applied to problems ranging from interstellar chemistry to molecular biology.

0-306-42152-6/approx. 200 pp./ill./1986

\section{DIGITAL \\ RADIOGRAPHY}

\section{Selected Topics}

edited by James G. Kereiakes, Stephen R. Thomas, and

\section{Colin G. Orton}

Many of the significant developments resulting from the applications of physics and engineering to digital radiography are described here by noted authorities in the field. 0-306-42188-7/approx. 200 pp./ill./1986 $\$ 39.50$ (\$47.40 outside US \& Canada)

\section{PRINCIPLES OF ENDOCRINE \\ PHARMACOLOGY}

by John A. Thomas and

\section{Edward J. Keenan}

Thomas and Keenan discuss a wide range of drug induced alterations in glandular secretions, drug-hormone interactions, and effects of drugs on clinical chemistry tests. Advances in recombinant DNA technologies are covered as they pertain to endocrine pharmacology, especially regarding recombinant human insulin and recombinant human growth hormone. 0306-42129-1/hardcover/310 pp./ill./1986 $\$ 39.50$ ( $\$ 47.40$ outside US \& Canada) 0-306-42143-7/paperback/310 pp./ill./1986 $\$ 22.50$ ( $\$ 27.50$ outside US \& Canada)

\section{PHARMACEUTICAL}

\section{RESEARCH}

\section{Official Journal of the}

American Association of Pharmaceutical Scientists Editor: Wolfgang Sadeé

Pharmaceutical Research provides excellent research in all areas of phar-

maceutical science including

- drug delivery

- computer-aided drug design

- biotechnology in drug developmeni

- novel methods of drug analysis

Subscription: Volume 3, 1986 (6 issues) Institutional rate:

$\$ 89.50$ in US $/ \$ 102.00$ elsewhere Personal rate:

$\$ 45.00$ in US $/ \$ 53.00$ elsewhere

Plenum Publishing Corporation 233 Spring Street New York, N.Y. 10013 In the United Kingdom 88/90 Middlesex Street London E1 7EZ, England 